\title{
Changing Pattern of Common Cancers in the Last Five Years in Kashmir, India: A Retrospective Observational Study
}

\author{
Nazir Ahmad Khan, MD ${ }^{1}$ Syed Nisar Ahmad, DM² Nazir Ahmad Dar, Msc Statistics ${ }^{1}$ \\ Shariq Rashid Masoodi, DM $^{3}$ Mohammad Maqbool Lone, MD $^{1}$
}

${ }^{1}$ Department of Radiation Oncology, Sheri Kashmir Institute of Medical Sciences (SKIMS) Soura, Srinagar, Jammu and Kashmir, India

2 Department of Medical Oncology, Sheri Kashmir Institute of Medical Sciences (SKIMS) Soura, Srinagar, Jammu and Kashmir, India

${ }^{3}$ Department of Endocrinology, Sheri Kashmir Institute of Medical

Sciences (SKIMS) Soura, Srinagar, Jammu and Kashmir, India

\author{
Address for correspondence Dr. Nazir Ahmad Khan, MD, Radiation \\ Oncology, SKIMS, Soura Srinagar, Jammu and Kashmir, India \\ (e-mail: drnazirkhan@rediffmail.com).
}

Ind J Med Paediatr Oncol 2021;42:439-443.

\begin{abstract}
Keywords

- cancer

- incidence

- smoking

- lifestyle

- food habits

Introduction Cancer is emerging as a major health problem worldwide. Profile and pattern of cancers vary as per the geographic, ethnic, and sociocultural background of the population. It is imperative to know the change in the pattern of cancer in the population to formulate an effective strategy for its control and management.

Objective To study the changing trends and epidemiological distribution of common cancer types in an ethnic population of Northern India.

Materials and Methods In this retrospective observational study, we audited records of 22,188 patients with histologically documented cancer registered between January 2014 and December 2018 in the regional cancer center of a tertiary care institute in North India. For all identified patients, medical records were reviewed for demographic information (age of diagnosis, sex, type of cancer, and select risk factors). The data analysis was done using IBM SPSS Statistics for Windows from IBM Corp. Data were expressed as frequencies with percentages. The incidence and trends were depicted through tables, and line diagrams were used to show the changes (if any) over the last 5 years.

Results The most common cancer reported in the last 5 years was lung cancer, overall (10.6\%; $95 \%$ confidence interval $[\mathrm{Cl}], 10.2-11.0)$ as well as in men $(14.8 \% ; 95 \% \mathrm{Cl}, 14.2-$ $15.4)$ and breast cancer in females $(13.5 \%$; $95 \% \mathrm{Cl}, 12.8-14.2)$. The top five cancers reported at our center were lung $(10.6 \%)$, esophagus $(9.1 \%)$, stomach $(9.0 \%)$, breast (6.0\%), and colon (3.8\%). Compared with that, the top five cancers reported from our center in 2012 were esophagus and gastroesophageal junction (17.2\%), lung (11.9\%), stomach $(9.7 \%)$, colorectal $(7.1 \%)$, and breast (6.5\%). Prostate cancer was reported in $3.4 \%$ of cases, which was much higher than that reported in $2012(1.7 \%)$. Surprisingly,
\end{abstract}

DOI https://doi.org/ 10.1055/s-0041-1740047. ISSN 0971-5851.
(C) 2021. Indian Society of Medical and Paediatric Oncology. All rights reserved.

This is an open access article published by Thieme under the terms of the Creative Commons Attribution-NonDerivative-NonCommercial-License, permitting copying and reproduction so long as the original work is given appropriate credit. Contents may not be used for commercial purposes, or adapted, remixed, transformed or built upon. (https://creativecommons.org/ licenses/by-nc-nd/4.0/)

Thieme Medical and Scientific Publishers Pvt. Ltd., A-12, 2nd Floor, Sector 2, Noida-201301 UP, India 
thyroid cancer (6.4\%) was the fourth commonest cancer reported in females, while it did not figure in the top 10 cancers in the 2012 report. Expectantly, cervix cancer did not figure among the top 10 cancers in women.

Conclusion There is a change in the pattern of cancers. Lung and breast have emerged as the most commonly occurring cancers in men and women, respectively, whereas there was a slight downward trend in the incidence of esophageal cancer.

\section{Introduction}

Non-communicable diseases are responsible for the most number of global deaths. ${ }^{1}$ Patients with cancer from lowand middle-income countries have a poor outcome due to various reasons such as lack of awareness, late presentation, and poor access to affordable medical services. ${ }^{2,3}$ The changing trends in cancer incidence and mortality are affected by various factors, which include population structure, education, and cancer screening program, health care availability and affordability, in addition to different ethnic, regional, and lifestyle factors. Kashmir is located at an altitude of 1,800 to $2,400 \mathrm{~m}$ above the sea level. It has a unique ethnic population with special cultural and dietary habits. ${ }^{4}$ The world has witnessed an increase in the incidence and change in the pattern of cancer. In this regard, we conducted this study to examine the increasing trend and epidemiological distribution of common cancer types over the period of last 5 years in this part of the country.

\section{Materials and Methods}

In this retrospective observational study, we audited records of 22,188 patients with histologically documented cancer. This was registered between January 2014 and December 2018 in our regional cancer center-a tertiary care center in North India. Besides our regional cancer center, data were collected from all identified pathology laboratories and other government/private institutions that manage cancer patients in the Kashmir valley. Great care was taken during data collection to present the actual figures during the study period. For all identified patients, medical records were

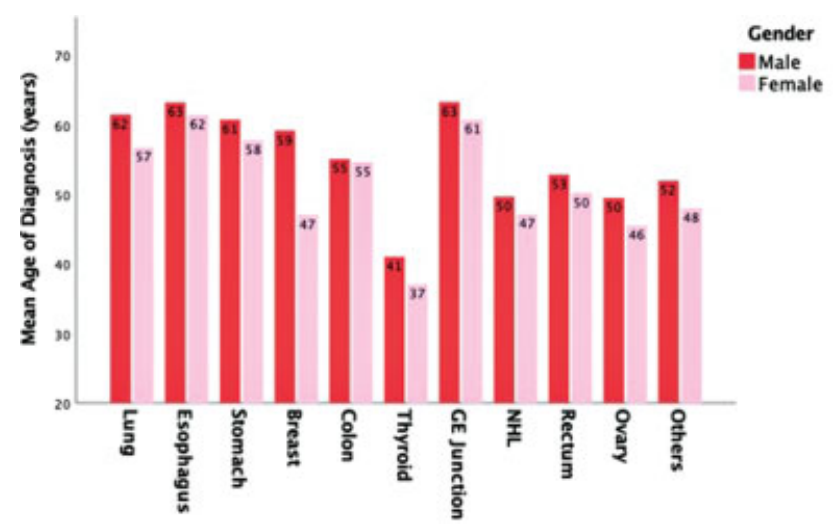

Fig. 1 Mean age of diagnosis (year). reviewed in detail. All the available information was noted and recorded in a proforma especially designed for this study. Detailed demographic information, particularly the age of diagnosis and gender of the study subjects, was noted. The type of cancer and some select risk factors were also noted (-Fig. 1).

\section{Sample Size}

Sample size was calculated on the basis of upper gastrointestinal (GI) tract cancers as they constitute the majority of the cases of cancers in the Kashmir valley. Presuming a prevalence of $30 \%$, we needed to study 3,585 cases of upper GI tract cancer at $95 \%$ confidence level with a relative error of $5 \%$. To account for incomplete records, a non-response rate of $10 \%$ was added. Cases made the sample size 3,944 for upper GI tract cancer and 13,147 for cancer. Ultimately, we studied 22,188 cases including 4,805 cases of upper GI tract cancer.

\section{Data Analysis}

Data were analyzed as per the main types of cancer separately as well as collectively for men and women. Patients with no histological evidence of malignancy were excluded from the study. The data collection criteria were age, gender, morphology, and histology. We have included all the recent publications; the old ones were included only where necessary.

\section{Primary Outcome}

To find the changing trend (if any) in the incidence of cancer over last 5 years in the Kashmir valley.

\section{Statistical Analysis}

Data analysis was done on an MS Windows-based PC computer. The data were first keyed into a Microsoft Excel spreadsheet and cleaned for any inaccuracies. Statistical analysis was done using IBM SPSS Statistics for Windows from IBM Corp. (released 2020, Version 27.0. Armonk, NY, USA). Categorical variables were shown in the form of frequencies and percentages. The incidence and trends were depicted through tables and figures, and line diagrams were used to observe any change over the last 5 years.

\section{Ethics}

The procedure in conducting the study was as per the institutional ethics committee guidelines and as per the Helsinki Declaration of 1964, revised in 2013. It was approved by the institutional ethics committee (IEC) of Sher-i- 
Table 1 Distribution of top 10 cancers by site $(n=22,188)$

\begin{tabular}{|l|l|l|l|}
\hline Site & Number of cases & Percent & $95 \% \mathrm{Cl}$ \\
\hline Lung & 2,348 & 10.58 & $10.18-10.99$ \\
\hline Esophagus & 2,009 & 9.05 & $8.68-9.44$ \\
\hline Stomach & 2,006 & 9.04 & $8.67-9.43$ \\
\hline Breast & 1,339 & 6.03 & $5.73-6.36$ \\
\hline Colon & 850 & 3.83 & $3.58-4.09$ \\
\hline Thyroid & 828 & 3.73 & $3.49-3.99$ \\
\hline GE junction & 790 & 3.56 & $3.32-3.81$ \\
\hline NHL & 711 & 3.20 & $2.98-3.44$ \\
\hline Rectum & 693 & 3.12 & $2.90-3.36$ \\
\hline Ovary & 678 & 2.83 & $8.68-3.29$ \\
\hline
\end{tabular}

Abbreviations: $\mathrm{Cl}$, confidence interval; GE Gastroesophageal Junction.

Kashmir Institute of Medical Sciences (SKIMS) no. IEC SKIMS 2017-94, dated 22-4-2017. Informed consent was waivered, as this was a retrospective audit of the health records. As only the anonymized data collected from medical records were used, the study protocol was exempted from full ethical review, and hence approved by the IEC in the exempted category.

\section{Results}

A total of 22,188 patients were registered during the study period. There were 12,695 male and 9,493 female patients with a male to female ratio of $1.33: 1$. There has been a persistent increase in the number of cases diagnosed each year; 3,890 cases in 2014 to 4,834 cases in 2018; $6 \%$ increase over a period of 5 years. Digestive tract cancers (25\%) constituted the major portion among the top 10 cancers (-Table 1). The majority (53\%) of the patients were within the age group of 35 to 64 years, with a mean age of $53.3 \pm 17.3$ years (median, 55 years). Men (median age, 60 years) were older than women (median age, 55 years) at diagnosis ( $56.0 \pm 17.0$ vs. $49.7 \pm 16.9 ; p<0.001$ ). Among the top 10 cancers, esophageal cancer had the highest age at presentation (mean age, 62.49 years), whereas the lowest age at presentation was seen in thyroid cancer (mean age, 38.13 years). Among the other common cancers, the mean age at diagnosis in the cancers of lungs, stomach, and breast were 60,60 , and 45 years, respectively. The most common cancer reported in the past 5 years was lung cancer, overall (10.6\%; 95\% confidence interval [CI], 10.2-11.0) as well as in men (14.8\%; 95\% CI, 14.2-15.4) and breast cancer in females (13.5\%; 95\% CI, 12.8-14.2). The top five cancers reported at our center were lung (10.6\%), esophagus $(9.1 \%)$, stomach (9.0\%), breast (6.0\%), and colon (3.8\%) (-Table 1). Among the top 10 cancers, there was $15 \%, 8 \%, 7 \%, 6 \%, 5 \%, 1.49 \%, 1.47 \%$, $0.74 \%$, and $0.73 \%$ increase in the number of cases of cancers of the thyroid, gastroesophageal junction, lung, breast, colon, stomach, ovary, NHL, and rectum, respectively, over a period of 5 years (-Fig. 2). However, there was a slight decline in the number of esophageal cancer cases (1.81\%).

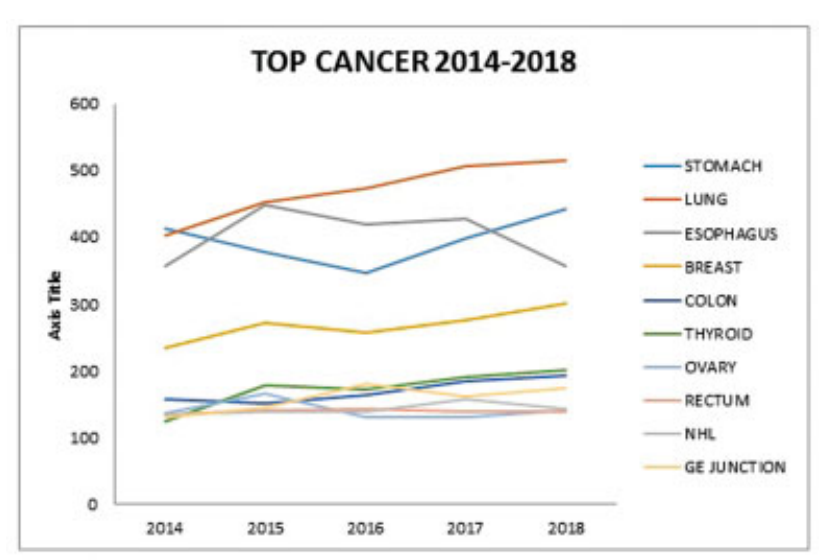

Fig. 2 Distribution of top 10 cancers by year wise.

\section{Discussion}

The current study revealed a changing trend in the pattern of cancer as observed over the last 5 years. The Kashmir valley, located in the mountainous regions of India and surrounded by the Himalayas, has a unique ethnic population with special dietary habits. The sociocultural and climate reasons have led to distinct, traditional, food habits such as consumption of sun-dried vegetables, meat, locally prepared vegetable pickles (ancher), large quantities of hot salted tea along with sodium bicarbonate (noon-chai), dried and smoked fish, red chilies, spice cake (wur) with vegetables such as Brassica oleracea (haak). Among all sedentary habits, a special type of tobacco use (hookah smoking) and use of a unique type of heating device (kangri) are considered to be the major risk factors for the digestive tract, lung, and skin cancers seen in this region. ${ }^{5}{ }^{9}{ }^{9}$ However, the most notable observation made in this study is that of esophageal cancer. It was previously the most common cancer type since the cancer data were available in the valley ${ }^{10,11}$ and is now showing a declining trend. Similar observations have been reported by other authors. ${ }^{12}$ This might be possible because of the above mentioned traditional dietary habits being reduced to a large extent. However, other digestive tract cancers such as those of the stomach, gastroesophageal (GE) junction, colon, and rectum have shown a gradual increase and continue to be amongst the top 10 cancers monitored during the study period (- Table 1; - - Fig. $\mathbf{3}$ ).

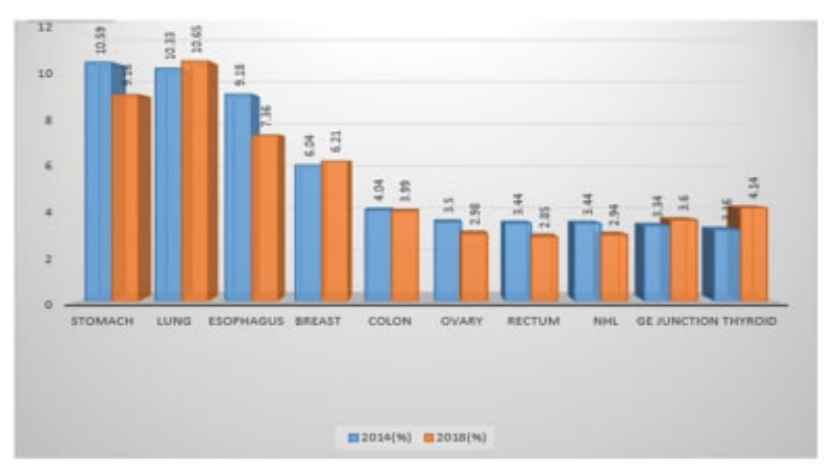

Fig. 3 Scenario of the Kashmir valley between 2014 and 2018. 
Table 2 Pattern of top 10 cancers (2014 vs. 2018)

\begin{tabular}{|l|l|l|l|l|l|l|l|}
\hline \multicolumn{2}{|l|}{$2014(\boldsymbol{n}=\mathbf{3 , 8 9 0})$} & $\mathbf{9}$ & $\mathbf{2 0 1 8}(\boldsymbol{n}=\mathbf{4 , 8 3 4})$ & $\mathbf{n}$ \\
\hline Site & $\mathbf{N}$ & $\%$ & $\mathbf{9 5 \%} \mathrm{Cl}$ & Site & $\boldsymbol{n}$ & $\%$ & $\mathbf{C} \%$ \\
\hline Stomach & 412 & 10.59 & $9.6-11.6$ & Lungs & 515 & 10.65 & $9.8-11.6$ \\
\hline Lungs & 402 & 10.33 & $9.4-11.3$ & Stomach & 443 & 9.16 & $8.4-10.0$ \\
\hline Esophagus & 357 & 9.18 & $8.3-10.1$ & Esophagus & 356 & 7.36 & $6.6-8.1$ \\
\hline Breasts & 235 & 6.04 & $5.3-6.8$ & Breasts & 300 & 6.21 & $5.5-6.9$ \\
\hline Colon & 157 & 4.04 & $3.4-4.7$ & Thyroid & 200 & 4.14 & $3.6-4.7$ \\
\hline Ovary & 136 & 3.50 & $2.9-4.1$ & Colon & 193 & 3.99 & $3.5-4.6$ \\
\hline Rectum & 134 & 3.44 & $2.9-4.1$ & GE junction & 174 & 3.60 & $3.1-4.2$ \\
\hline NHL & 134 & 3.44 & $2.9-4.1$ & Ovary & 144 & 2.98 & $2.5-3.5$ \\
\hline GE junction & 130 & 3.34 & $2.8-3.7$ & NHL & 142 & 2.94 & $2.5-3.4$ \\
\hline Thyroid & 123 & 3.16 & $2.6-3.8$ & Rectum & 138 & 2.85 & $2.4-3.4$ \\
\hline
\end{tabular}

Abbreviations: $\mathrm{Cl}$, confidence interval; GE Gastroesophageal junction, NHL Non-Hodgkins Lymphoma.

Lung cancer was at number two among top cancers in males as per the available literature until date. It has shown an increasing trend, which was persistently observed for last 5 years and is now ranking number one $(10.58 \%$ ) ( - Table $\mathbf{1}$ ). Smoking has been associated with lung cancer by innumerable studies. ${ }^{13}{ }^{17}$ In this region, besides cigarette smoking, we have a popular tradition of hookah (hubble bubble) smoking, where smoke is inhaled after it passes through the water placed in an earthen container through which it gets filtered and cooled. This is also one of the important causes of passive smoking of family members, especially during winters. Because smoking is not popular among females in this region, it justifies the fact that lung cancer is not common in females (4.95\%). ${ }^{18,19}$

Cancer of prostate has appeared amongst the top 10 cancers and accounts for $3.4 \%$ of all cancers in the valley (-Table 1). Prostate cancer is the leading cancer in the most of the western countries and is showing a consistent increasing trend in India. ${ }^{20} \mathrm{An}$ important observation made in this study was that of an increase in breast cancer that has surpassed esophageal cancer and has become number one, accounting for $13.53 \%$ of all cancers amongst females (-Table 1). Similarly in India, breast has emerged as the leading site of cancer among women. ${ }^{21}$ The other cancers that have an increasing trend and are among top 10 cancers in women include ovary (7.4\%), thyroid (6.4\%), and gallbladder (3.5\%) (-Table 1). Surprisingly, cancer of the cervix (0.64\%) does not figure among top 10 cancers in females and does not show any changing trend over the years. However, in India, decreasing trend of cervical cancer has been reported from some areas. The decline can be associated with the improvement in the living standards of women (-Supplementary Fig. S1).22,23

Skin cancer usually called "kangri cancer" in this region was first reported by Maxwell T. in $1819 .{ }^{24}$ It has shown a decline amongst females and continues to be amongst top 10 cancers in males, accountings for $1.83 \%$ of all male cancers (-Table 1). It is a unique type of cancer, where the main causative factor is kangri exposure. Kangri is an earthenware portable brazier used during winters, kept under a loose gown. Kangri cancer is squamous cell cancer of skin peculiarly persisting on the anteromedial aspects of thighs, abdominal wall exposed to intense heat and to secondary combustion of charcoal. The disease starts with an erythematous patch on skin, which transfers into pink to dark serpiginous patches, finally to cancer, ${ }^{25}{ }^{28}$ whereas all over the world exposure to the sun is considered to be the causative factor for skin cancer.

Head and neck cancers comprise $5 \%$ of all malignancies worldwide. ${ }^{29}$ In the current study, these cancers were not common, accounting for $2.85 \%$ of all cancers and did not show any change over the years, of which larynx cancer is the most common (28.54\%), followed by nasopharyngeal cancer (22.5\%). Oral cancers are leading in the Indian subcontinent since its incidence is associated with tobacco, pan, and gutkha and betel nut chewing. ${ }^{30,31}$ This tradition is not seen in the valley, justifying the low incidence $(0.77 \%)$ of oral cancers (tongue, lip, and mouth) in this region. There is a paucity of data available regarding the pattern of childhood malignancies in this part of the country; the current study revealed the pediatric tumors constituted $1.79 \%$ of all the malignancies. The non-hematological malignancies were more common (52.01\%) than the hematological malignancies (47.98\%). Overall, acute lymphoblastic leukemia is the most common and accounts for $39.69 \%$ of pediatric tumors.

Hematological cancers accounts for $10.69 \%$ of all cancers, of which non-Hodgkin's lymphoma continues to be among the top 10 cancers, it accounting for $20.41 \%$ and $10.01 \%$ among males and females, respectively ( - Table 1 ). We observed a slight decline in the incidence of non-Hodgkin's lymphoma (3.44\% in 2014 to $2.94 \%$ in 2018) (-Table 2).

Brain tumors, overall, accounted for $0.74 \%$ of all cancers and did not feature in among the top 10 cancers. Astrocytoma was the most common, accounting for $39.54 \%$ of brain tumors.

Tobacco-related cancers in this study contributed to $\sim 21.95 \%$ of all cancers. The population-based cancer registry in India has shown that tobacco-related cancers contribution 
to nearly half and one-fifth of cancers in males and females, respectively. $^{32}$

In future, the study will act as a guide for cancer awareness, prevention, and early detection. In addition, the management policy will be decided according to the changing pattern of cancers.

\section{Limitations}

The limitations in this study is that cancer incidence data alone will not be a sufficient guide to study the change in the trend because cancer prevalence, particularly that of acute cases, have a significant impact on the trend. Therefore, a comprehensive detail of risk factors and etiopathogenesis is required.

\section{Conclusion}

With time, changes in the lifestyle and sociocultural habits alter the pattern of cancer. This study will serve as an impetus for reshaping the clinical practice in terms of detection, prevention, and treatment of various cancer types.

\section{Conclusion}

The study will act as a guideline for creating a management policy for the administration and clinicians.

Funding

Sheri Kashmir Institute of Medical Sciences,Srinagar,UT J\&K, India

\section{Conflict of Interest}

None declared.

\section{References}

1 Bray F, Ferlay J, Soerjomataram I, Siegel RL, Torre LA, Jemal A. Global cancer statistics 2018: GLOBOCAN estimates of incidence and mortality worldwide for 36 cancers in 185 countries. CA Cancer J Clin 2018;68(06):394-424

2 Chalkidou K, Marquez P, Dhillon PK, et al. Evidence-informed frameworks for cost-effective cancer care and prevention in low, middle, and high-income countries. Lancet Oncol 2014;15(03): e119-e131

3 Sivaram S, Majumdar G, Perin D, et al. Population-based cancer screening programmes in low-income and middle-income countries: regional consultation of the International Cancer Screening Network in India. Lancet Oncol 2018;19(02):e113-e122

4 Ayub SG, Ayub T, Khan SN, et al. Epidemiological distribution and incidence of different cancers in Kashmir valley-2002-2006. Asian Pac J Cancer Prev 2011;12(07):1867-1872

5 Dhar GM, Shah GN, Naheed B, Hafiza . Epidemiological trend in the distribution of cancer in Kashmir Valley. J Epidemiol Community Health 1993;47(04):290-292

6 Qazi MI, Ganai AM, Bhat GM, Fazili AB. Pattern and magnitude of various cancers registered at regional cancer centre of a tertiary care institute in north india. Int J Community Med Public Health 2016;3(6):1672-1680

7 Siddiqi M, Preussmann R. Esophageal cancer in Kashmir-an assessment. J Cancer Res Clin Oncol 1989;115(02):111-117

8 Siddiqi M, Kumar R, Fazili Z, Spiegelhalder B, Preussmann R. Increased exposure to dietary amines and nitrate in a population at high risk of oesophageal and gastric cancer in Kashmir (India). Carcinogenesis 1992;13(08):1331-1335

9 Khan NA, Teli MA, Mohib-Ul Haq M, Bhat GM, Lone MM, Afroz F. A survey of risk factors in carcinoma esophagus in the valley of Kashmir, Northern India. J Cancer Res Ther 2011;7(01):15-18

10 Khuroo MS, Zargar SA, Mahajan R, Banday MA. High incidence of oesophageal and gastric cancer in Kashmir in a population with special personal and dietary habits. Gut 1992;33(01):11-15

11 Khan NA, Lone MM, Afroz F, Kharadi MY. Clinopathological profile of carcinoma esophagus and esophagogastric junction in Kashmir. JK Pract 2004;11:182-185

12 Wani MA, Jan FA, Khan NA, Pandita KK, Khurshid R, Khan SH. Cancer trends in Kashmir; common types, site incidence and demographic profiles: National Cancer Registry 2000-2012. Indian J Cancer 2014;51(02):133-137

13 Behera D, Balamugesh T. Lung cancer in India. Indian J Chest Dis Allied Sci 2004;46(04):269-281

14 Maghfoor I, Perry MC. Lung cancers. Ann Saudi Med 2005;25(01): 1-12

15 Janerich DT, Thompson WD, Varela LR, et al. Lung cancer and exposure to tobacco smoke in the household. N Engl J Med 1990; 323(10):632-636

16 Boyle P. The hazards of passive- and active-smoking. N Engl J Med 1993;328(23):1708-1709

17 Khan NA, Teli MA, Katosh S, Abrol D, Gupta M. The effect of smoking habits on different histological types of lung cancer in Kashmir. JK Science Journal of Medical Education and Research Jan-Mar,2008;10(01):23-25http://www.jkscience.org

18 Koul PA, Hajni MR, Sheikh MA, et al. Hookah smoking and lung cancer in the Kashmir valley of the Indian subcontinent. Asian Pac J Cancer Prev 2011;12(02):519-524

19 Khan NA, Afroz F, Lone MM, Teli MA, Muzaffar M, Jan N. Profile of lung cancer in Kashmir, India: a five-year study. Indian J Chest Dis Allied Sci 2006;48(03):187-190

20 Ramnath T, Nandakumar A. Estimating the burden of cancer. Natl Med J India 2011;24(02):69-71

21 Pandith AA, Siddiqi MA. Burden of cancers in the valley of Kashmir: 5 year epidemiological study reveals a different scenario. Tumour Biol 2012;33(05):1629-1637

22 Takiar R, Nadayil D, Nandakumar A. Projections of number of cancer cases in India (2010-2020) by cancer groups. Asian Pac J Cancer Prev 2010;11(04):1045-1049

23 D'Souza ND, Murthy NS, Aras RY. Projection of cancer incident cases for India -till 2026. Asian Pac J Cancer Prev 2013;14(07):4379-4386

24 Maxwell T. Epithelioma in Kashmir. Lancet 1879;113:152-154

25 Elmslie WJ. Etiology of epithelioma among the Kashmiris. Ind Med Gaz 1866;1(11):324-326

26 Neve A. Kangri-burn epithelioma in Kashmir. Ind Med Gaz 1900; 35(03):81-83

27 Khan NA. Role of elective irradiation to drainage sites in squamous cell carcinoma trunk and extremities. J Med Phys 1998;23(3):131-132

28 Aziz SA, Hussain KS, Ahmad KN, Ahmed M, Kharadi MY, Bhat JR. Profile of Kangari cancer: a prospecive study. Burns 1998;24(08): 763-766

29 Parkin DM, Pisani P, Ferlay J. Estimates of the worldwide incidence of 25 major cancers in 1990. Int J Cancer 1999;80(06):827-841

30 Malik A, Mishra A, Garg A, Shetty R, Mair M, Chakrabarti Set al. Trends of oral cancer with regard to age, gender, and subsite over 16 years at a tertiary cancer Centre in India. Indian J Med Paediatr Oncol 2018;39(03):297-300

31 Dikshit RP, Kanhere S. Tobacco habits and risk of lung, oropharyngeal and oral cavity cancer: a population-based case-control study in Bhopal, India. Int J Epidemiol 2000;29(04):609-614

32 Asthana S, Patil RS, Labani S. Tobacco-related cancers in India: a review of incidence reported from population-based cancer registries. Indian J Med Paediatr Oncol 2016;37(03):152-157 